\title{
Public Health Implication and Tackling Approaches of Veterinary Antibiotic Drug Resistance: Updated Review
}

\author{
Tekalign Tadesse ${ }^{1 *}$, Dame Koricho ${ }^{2}$ and Mohammed Seid ${ }^{1}$ \\ ${ }^{1}$ Bedele College of Agriculture and Forestry, Mettu University, Ethiopia \\ ${ }^{2}$ College of Veterinary Medicine, Samara University, Ethiopia
}

Submission: November 23, 2018; Published: December 07, 2018

*Corresponding author: Tekalign Tadesse, Bedele College of Agriculture and Forestry, Mettu University, Ethiopia

\begin{abstract}
Antibiotics are natural substance produced by microorganism that may inhibit or destroy the growth of other microbes. Antibiotics have paid to the exponential fall in death and illness from infectious and infectious diseases globally. However, currently, the clinical power of drugs is getting down and down due to resistance development by the infectious pathogens. Emergence of antibiotics resistance is a result of the use, overuse and misuse of antibiotics both in humans and animals. The molecular mechanisms are way by which bacteria are either inherently resistant or obtain resistance to antibiotics, including the prevention of access to drug targets, changes in the structure and protection of antibiotic targets and the direct modification or inactivation of antibiotics. If control measures are not taken, the world will face the very real possibility of a return to non-treatable infections. This result increased animal disease morbidity and mortality, increased animal healthcare costs and reduced efficacy to related antibiotics used in veterinary medicine. Beside this, resistant antibiotic resistant strains can be transmitted to human and cause serious problem. Since the effects and complications of drug resistance is intricate, the involvements sound for multidimensional approaches with full participation of all concerned bodies.
\end{abstract}

Keywords: Antibiotic; Drug resistance; Public health; Tackling

Abbreviations: AMR: Antimicrobial Resistance; MRSA: Methicilin Resistance Staphylococci Auras; GDP: Gross Domestic Product; PABA: ParaAminobenzoic Acid;

\section{Introduction}

The era of antibiotics led to optimism till the early 1970s that infectious diseases can be controlled and prevented, and mankind felt confident that modern medicine would prevail [1]. When antibiotics were first introduced in the 1930s and 1940s, they were regarded as 'miracle drugs' because they brought about significant reductions in mortality due to microbial diseases [2]. However, currently, the medical influence of drugs is getting low and low due to resistance growth by the infectious pathogens. Emergence of antibiotics resistance is a result of the use, overuse and misuse of antibiotics both in humans and animals. Antimicrobial resistance is a crucial challenge that veterinarian and human health service is facing today and is developing at an alarming pace. Resistance often occurs within months of the release of new antibiotics and the resistance incidence rates outstrip drug discovery and the development of new antibiotics. The world is now facing the very real possibility of a return to non-treatable infections. To make matters worse, many bacteria have become resistant to multiple antibiotics. Antibiotic resistance is not a recent phenomenon, but it is a critical health issue today both in animals \& man. The situation is much worse currently but has received too little attention [3].
In Ethiopia, there are clues on the misuse of antibiotics by health care providers, these joined with quick blowout of resistant bacteria and insufficient investigation contributed to the problem [4]. Studies on antibacterial resistance and the prevention and containment have received far too little attention. The consequences of these increased mortality, morbidity, costs of treatment, and loss of animal's production in [3]. Therefore, the objectives of this review are:

a. To assemble literature on the causes and mechanism of veterinary antibiotic drug resistance

b. To review the economic and public Health impact of Veterinary antibiotic drug resistance

c. To highlight the ways of tackling the antibiotic resistance and challenges.

\section{Antibiotic Resistance}

Antibiotic resistance is a type of drug resistance and a situation where a microorganism has developed or acquired the ability to 
survive the presence of an antibiotic. In other way it is the ability of bacteria to repel the effects of an antibiotic. It is a bacteria's way of surviving [5]. This resistance can be acquired through horizontal gene transfer, unlinked point mutation in the pathogen genome or chromosomal aberration and subsequent replication [6]. Although antibiotic resistance is a natural biological phenomenon, it often enhanced because of infectious agents' adaptation to exposure to antibiotic used in humans or agriculture and the wide spread use of disinfectants at the farm and the household levels. It is now accepted that antibiotic use is the single most important factor responsible for increased antibiotic resistance [7]. Antibiotics resistance is currently the greatest challenge worldwide. It decreases the effectiveness of drugs that decrease morbidity and mortality associated with serious and life-threatening infections and thus, compromising animal health. Antibiotic-resistant strains of pathogenic bacteria are increasingly prevalent and represent a priority health problem [8]. Hence, the problem of antibiotic resistance needs an urgent response. Developing a new antibiotic can take years and millions of dollars [9].

\section{Cause of Antibiotic Resistance}

Antibiotic resistance is a natural phenomenon; i.e., survival of the fittest and the ability of bacteria to repel the effects of an antibiotic. Once an antibiotic was effective in killing a bacteria, the development of antibiotic resistance is a bacteria's way of surviving in its environment. Antibiotic resistance results from one of three types of gene action: spontaneous DNA mutation, transformation, and plasmid transfer. There are many other factors which contribute to the rising incidence of resistance in animal pathogens. These factors include liberal availability of antibiotic in some countries and Societal factors such as the increasing number of immune-compromised animals, unnecessary antibiotic use caused by patient demands for antibiotic treatment of viral infections, the changing animal population age structure, and an increase in institutional care environments In these environments large numbers of susceptible animals in close physical contact, and with high incidence of antibiotic use, promote transmission of resistant microbes and/or factors. In addition, increasing international travel and trade allows resistant organisms to quickly disseminate globally.

Owner often put pressure on veterinarian to provide their animals with antibiotics for coughs, colds, and the flu. Most of the time, these infections are caused by viruses and viruses do not respond to treatment with antibiotics. The owner sometimes stops to giving antibiotics to patients' animals for bacterial infections as soon as they start feeling better. By not finishing the entire dose of antibiotics, resistant bacteria not killed in the first days of antibiotic treatment will continue to multiply. Owner often take antibiotics that were left over from a previous illness to treat a current illness. Sometimes an antibiotic prescribed for one animal is "loaned" to another animal to treat an infection. These practices increase the likelihood of antibiotic resistance [10].

The major problem of the emergence of resistant bacteria is due to misuse and overuse of antibiotics by professionals as well as patients/owners. In some developing countries, many professionals treat many infections for long before requesting for laboratory investigations, that is, when the patient fails to respond well to initial treatment. Such practice is usually due to lack of good laboratory facilities in the environment or under-use of the laboratory or outright disregard for laboratory diagnosis by clinicians [11].

\section{Mechanisms of Antibiotic Drug Resistance}

The molecular mechanism of antibiotics resistance genetically divided into two categories: intrinsic resistance and acquired resistance. Some bacteria are naturally resistant to certain antimicrobial agents and their resistance is Irrespective of the introduction of antimicrobial agent. Such a resistance is said to be intrinsic. Examples include ampicillin/cephalosporin resistance in enterococcus and amino glycoside resistance in non-spore anaerobes. Most other bacteria develop resistance due to mutation following exposure to antimicrobial agents or receive resistant property passively from resistant organisms. Such resistance is called acquired resistance. It is the latter that is more worrisome and antimicrobial agents previously known to be effective are turning out to be ineffective [12].

\section{Inactivation of the Antimicrobial Drug}

Bacteria have evolved several mechanisms of rendering antibiotics inactive such as the enzymatic hydrolysis of antibiotics, group transfer and the redox process. The classical example of this mechanism is the production of $\beta$-lactamases that hydrolyze the $\beta$-lactam ring of penicillin. The genes encoding $\beta$-lactamases (bla) are either on the chromosome (e.g. AmpC $\beta$-lactamase) or on the plasmids, the TEM- $1 \beta$-lactamase being the first one to be discovered on the plasmid in a strain of Escherichia coli [13].

\section{Alteration of the Antimicrobial Target}

Natural variations or acquired changes in the target sites of antimicrobials that prevent drug binding or action is a common mechanism of resistance. Target site changes often result from spontaneous mutation of a bacterial gene on the chromosome and selection in the presence of the antibiotics [14]. Some antibiotics have binding proteins on the cell walls of sensitive microorganism e.g. penicillin-binding protein. Alterations in such proteins will bring about development of resistance against such microorganisms. Examples are the binding target site of penicillin in methicillin-resistant Staphylococcus aureus (MRSA) [15].

Adaptation of Alternative metabolic Pathway. Some sulfonamide-resistant bacteria do not require para-aminobenzoic acid (PABA), an important precursor for the synthesis of folic acid and nucleic acids in bacteria inhibited by sulfonamides. Instead, like mammalian cells, they turn to utilizing preformed folic acid. This makes it easy for such microorganisms to develop resistance.

\section{Active Efflux Pumping Out of the Drug}

One of the most common drug resistance mechanisms is active efflux of drugs from the inside of bacterial cells. Such drug resistant bacteria harbor energy-driven drug efflux pumps which 
extrude antimicrobial agents thus reducing their intracellular concentrations to sub- or non-inhibitory levels [16]. These efflux pumps are variants of membrane pumps possessed by all bacteria, to move lipophilic or amphipathic molecules in and out of the cells. Some are used by antibiotic producers to pump antibiotics out of the cells as fast as they are made, and so constitute an immunity protective mechanism for the bacteria to prevent being killed by their own chemical weapons [17].

\section{Reduced Permeability}

Decreased permeability of the drug, a drug resistant phenotype of a bacterium may be due to the inability of the antimicrobial agent to enter the cell where the drug targets are located. Compared with Gram-positive species, Gram-negative bacteria are intrinsically less permeable to many antibiotics as their outer membrane forms a permeability barrier [18].

\section{Status of Antibiotic Drug Resistance in Ethiopia}

In Ethiopia, there are indications on the misuse of Antimicrobials by health care providers', unskilled practitioners, animal husbandry and drug users. These coupled with rapid spread of resistant bacteria and inadequate surveillance has exacerbated the problem. Infectious diseases, along with nutritional problems are the major cause of morbidity and mortality in Ethiopia. The Department of Disease Prevention and Control of the Ethiopian Ministry of Health $(\mathrm{MoH})$ reports that, "the country's most important health problems are communicable diseases and antimicrobial drug resistance [19].

The several constraints in Ethiopia that cause the above problems are: No infection control committees in institutional settings, drug quality concerns, especially in rural and around border areas, unregistered drugs and drug sellers in rural area, long stock-outs of essential drugs in veterinarian facilities and weak storage capacity of pharmaceuticals. Not only these but low availability of standard treatment at clinical facilities, poor dispensing practices, low owner knowledge about drugs dispensed to their animals and lack of antibiotic policy are additional factors.

\section{Public Health Impact of Antibiotic Drug Resistance}

Antibiotic usage in animal results in the developments of human MARSA which results in amplified human illness, death, reduced effectiveness of associated antibiotics used for human, increased healthcare costs, increased potential for carriage and dissemination of pathogens within human populations and facilitated emergence of resistant human pathogens [20]. The research estimated that, under the circumstances enumerated below, 300 million people are expected to die prematurely because of drug resistance over the next 35 years and the world's GDP will be 2 to $3.5 \%$ lower than it otherwise would be in 2050 . This means that between now and 2050 the world can expect to lose between 60 and 100 trillion USD worth of economic output if antimicrobial drug resistance is not tackled. This is equivalent to the loss of around one year's total global output over the period and will create significant and widespread human suffering. Furthermore, in the nearer term we expect the world's GDP to be $0.5 \%$ smaller by 2020 and $1.4 \%$ smaller by 2030 with more than 100 million people having died prematurely [21].

Acquirement of resistance bacterial species for human being can be from food of animal origin and infected animal [22]. Methicillin-resistant Staphylococcus Aureus (MRSA) is resistant bacteria which are not affected by enzyme penicillinase. Currently animals are a source of human MRSA which is responsible for zoonotic implication [23].

\section{Economic Impact of Antibiotic Drug Resistance}

Because of their increased survivability in the existence of antibiotic meditations, infectious agents keeping AMR received an enhanced possibility for spread, occurrence. Which cause in their supremacy over the predominant microorganism within animal host populations, resulting in advanced rates of spread as related to the vulnerable bacterial species [24]. Initial research, looking only at part of the impact of AMR, shows that a continued rise in resistance by 2050 would lead to 10 million people dying every year and a reduction of $2 \%$ to $3.5 \%$ in Gross Domestic Product (GDP). It would cost the world up to 100 trillion USD. An increased medical charge is extra vital result of antibiotic resistance. Increased prices may be owing to the prerequisite for supplementary antibiotic treatments, longer hospitalization, more diagnostic tests, higher professional costs and more pain management or Antibiotic resistance due to an antibiotic used in animals may result in reduced efficacy of most or all members of that same antibiotic class [25].

\section{Strategies of Tackling Antibacterial Drug Resistance}

Several plans and tactics have tried to deal through resistance. The term "control" seems inapt since correct control of antimicrobial resistant organisms and their effects seems naturally and historically difficult. However, reports from expert societies, reviewer groups, and constitutional Agencies pressure several actions to diminish the damaging properties of resistance [26]. The best evident way to fight resistance is to improve new antimicrobial agents. Numerous novel mixtures or kind of antimicrobial agents currently may show appreciable to fight infections produced by resistant microorganisms. Nonantimicrobial means to struggle resistant organisms (e.g., production of vaccines) will also undertake more importance [27]. Surveillance has paramount importance in determining actions required to switch antimicrobial drug resistance. Novel, quick laboratory procedures are becoming presented to simplify this significant effort [28].

Emerging antimicrobial-drug resistance affects the ability of the clinical microbiology laboratory to detect and report resistance. Several new resistance mechanisms in gram-positive and gram-negative bacteria organisms are difficult to detect with usual laboratory methods. To counter these problems, new testing methods, as well as guidelines and standards for testing resistant organisms should be developed. Physicians, students, residents, veterinarians, pharmacists, infection control and quality assurance 
personnel, administrative staff, and others are frequently part of the health-care team [29].

Making sure that cognizance of the effect of drug resistance and how to move through it are part of the learning program. Veterinarian institutes are shifting their curriculums to assure veterinarian studies when and how to recommend antibiotics and expert is getting updated evidence on correct antibiotic usage. The community is being cultivated about the right practice of antibiotics and means to use to curtail the probable of diet poisoning. Pharmacists are being invigorated to deliver "narrow spectrum" antibiotics, which mark only a few bacterial types, when possible. This is a modification from the custom of broad spectrum antibiotics, which is active against a whole host of bacteria types. Current concern has engrossed on improving antimicrobial drug use by regulating the best of antimicrobial agents by single prescribers. Some stated struggles attempt to bound habit of incorrect agents by eliminating exact drugs from the list of accessible agents in the formulary or limiting them to few specialists [30-36].

\section{Conclusion and Recommendations}

The threat of drug miss-use and resistance is growing at an alarming pace, perhaps more rapidly in Ethiopia [37-40]. This is because, in most districts of Ethiopia, antibiotic drugs are widely available to the public, without effective controls. In order to maximize the benefits of antibiotics and minimize the potential development of resistance it would be judicious for all uses of antibiotics to be re-examined. If the spread of antibiotic resistance is not got under control, common bacterial contaminations may once again be blamable for the deaths of indefinable numbers of people/animals and the world will changed to non-treatable infection [41]. This will result a significant public health and economic impact. Since the causes and problems of drug resistance is difficult, the interventions call for complex approaches with full involvement of all participants including health care facilities, policy makers, regulatory authority, professionals, universities, training and research institutions and the community [42].

Therefore, based on the above facts the following recommendations will be forwarded:

a. Antibiotics should be taken only with veterinarian directions. Don't take antibiotics for your animal that left over from old prescriptions, given to you by friends or family or purchased without prescription.

b. Peoples should not absolutely depend on antibiotics for themselves and their animals.

c. Finishing each antibiotic prescription for your animals even if the animal feels better. If they don't, some resistant bacteria may stay with them and multiply, requiring a different and likely stronger antibiotic when the infection returns weeks later.

d. Health professionals should have to provide drugs, the right drugs shall be used for the right indications in the right dose and dosage form for the right duration by the right professional considering the right animal and public health concern.

\section{References}

1. Bockstael K, Aerschot A (2008) Antimicrobial resistance in bacteria: Central European Journal of Medicine 4: 141-155.

2. Caprioli A, Busani L, Martel J, Helmuth R (2000) Monitoring of antibiotic resistance in bacteria of animal origin. Epidemiological and microbiological methodologies: Int J Antimicrob Agents 14: 295-301.

3. Byarugaba D, Kisame R, Olet S (2011) Multi-drug resistance in commensal bacteria of food of animal origin in Uganda: Afr J Microbiol Res 5: 1539-1548.

4. Drug Administration and Control Authority of Ethiopia (DACA) (2009) Antimicrobials use, resistance and containment baseline survey syntheses of findings: p. 1-91.

5. Lucia J (2006) antibiotic resistance $\left(26^{\text {th }}\right.$ edn), Management Sciences for Health p. 2-11.

6. Anonymous (2011) Possible Alternatives to Reduce Antibiotic Resistance 24:1-9.

7. World Health organization (2014) Antimicrobial resistance: global report on surveillance.

8. Livermore D, Macgowan A, Wale M (1998) Surveillance of antimicrobial resistance. British Medical Journal 317: 614-615.

9. Falagas M, Karageorgopoulos D (2008) Pan Drug resistance (PDR), extensive drug resistance (XDR), and multidrug resistance (MDR) among gram-negative bacilli need for international harmonization in terminology: Clin Infect Dis 46: 1121-1122.

10. Gassman N, Blumerich W, Celiste Skouson R (2006) Antibiotic Resistance, gram-negative bacteria, clinical profile, therapeutic management, and outcome in a series of 21 patients. Eur J Clin Microbiol Infect Dis 29: 301-315.

11. World Health Organization (2002) Use of antimicrobials outside human medicine and resultant antimicrobial resistance in humans. World Health Organization Fact Sheet No. 268.

12. Anonymous (2012) Antibiotics and antibiotic resistance.

13. Davies J (1994) Inactivation of antibiotics and the dissemination of resistance genes. Science New York, USA, 264: 375-382.

14. Lambert $P$ (2005) Bacterial resistance to antibiotics: modified target sites. Adv Drug Deliv Rev: 57: 1471-1485.

15. Cirz R, Chin J, Andes D (2005) Inhibition of mutation and combating the evolution of antibiotic resistance. PLoS Biology 3: 176.

16. Webber M, Piddock L (2003) The importance of efflux pumps in bacterial antibiotic resistance. The Journal of antimicrobial chemotherapy 51: 9-11.

17. Walsh C (2000) Molecular Mechanisms that Confer Antibacterial Drug Resistance Nature, 406: 775-781.

18. Kojima S, Nikaido H (2013) Permeation rates of penicillin indicate that Escherichia coli porins function principally as nonspecific channels 110: $2629-2634$.

19. EFDR Ministry of Health (2005) Guidelines for the Prevention and Control of Selected Major Epidemic Diseases in Ethiopia. Addis Ababa Department of Disease Prevention and Control.

20. Aarestrup F, Wegener H, Collignon P (2008) Resistance in Bacteria of the food chain epidemiology and control strategies. Anti. Infect 6: 733750 .

21. Jim O'Neill m (2014) The Review on Antimicrobial Resistance. 1: 1-26. 
22. Hendriksen S, Orsel K, Wagenaar J, Miko A, van Duijkeren E (2004) Animal-to-Human Transmission of Salmonella Typhimurium DT104A Variant: Emerging Infectious Diseases: 10: 2225-2227.

23. Lee J (2003) Methicillin (Oxacillin)-resistant Staphylococcus aureus Strains Isolated from Major Food Animals and Their Potential Transmission to Humans. Applied and Environmental Microbiology 69: 6489-6494.

24. Angulo F, Nunnery J, Bair H (2004) Antimicrobial resistance in zoonotic enteric pathogens. Rev Sci tech Off Int Epiz 23: 485-496.

25. McDonald L, Rossiter S, Mackinson C, Wang Y, Johnson S, et al. (2001) Quinupristin Dalfopristin resistant Enterococcus faecium on chicken and in human stool specimens. New England Journal of Medicine: 345 $1155-1160$

26. McGowan J (2001) Ways and means to influence antimicrobial prescribing in healthcare and its impact on resistance.

27. Dagan R, Givon L, Shkolnik L, Yagupsky P, Fraser D (2000) Acute otitis media caused by antibiotic-resistant Streptococcus pneumoniaein southern Israel implication for immunizing with conjugate vaccines: J of Infecteous Diseas: 181: 1322-1329.

28. Wise R, Andrews J (1998) Local surveillance of antimicrobial drug resistance. Lancet: 352: 657.

29. National Committee for Clinical Laboratory Standards (2000) Performance Standards for Antimicrobial Susceptibility Testing. Tenth Informational Supplement (Publication M100-S10). Villanova, Pennsylvania p.19.

30. Johnson A (2006) Daptomycin in the treatment of skin, soft-tissue and invasive infections due to Gram positive bacteria. Microbiol 1: 255-265.

31. Brown J (2006) What the Heck is Antibiotic Resistance. p. 1-6.
32. Delcour A (2009) Outer membrane permeability and antibiotic resistance. Biochimicaetbiophysicaacta 1794: 808-816.

33. EFDR Ministry of Health (2005) Guidelines for the Prevention and Control of Selected Major Epidemic Diseases in Ethiopia. Addis Ababa Department of Disease Prevention and Control.

34. Helms M, Vastrup P, Gerner-Smidt P, Molbak K (2002) Excess Mortality Associated with Antimicrobial Drug-Resistant Salmonella Typhimurium. Emerging Infectious Diseases 8: 490-495.

35. Hoiby M, Bjarnsholt T, Givskov M, Molin S, Ciofu O (2010) Antibiotic resistance of bacterial biofilms: International journal of antimicrobial agents 35: 322-332.

36. Kallen A, Hidron A, Patel J, Srinivasan A (2006) Multidrug resistance among gram negative.

37. Livermore D (2009) Has the era of untreatable infections arrived? J Antimicrobial. Chemother 64(3): 29-36.

38. Maria M, Mohan J (2006) visited Addis Ababa to help initiate the activity.

39. Roberts MC (2005) Update on acquired tetracycline resistance genes. FEMS microbiology letters) 245: 195-203.

40. Sturdy A, Goodman A, Jose R, Loyse A, O'Donoghue M, Kon 0 (2011) Multidrug-resistant tuberculosis (MDR-TB) treatment in the UK: a study of injectable use and toxicity in practice. Journal of Antimicrobial Chemotherapy: 66: 1815-1820.

41. Tsioutis C, Kritsotakis E, Maraki S, Gikas A (2010) Infections by pandrug-resistant.

42. Wright G, Johnston N, Mukhtar T (2002) Streptogramin antibiotics: mode of action and resistance. Curr Drug Targets: 3: 335-344.

Your next submission with Juniper Publishers
will reach you the below assets
- Quality Editorial service
- Swift Peer Review
- Reprints availability
- E-prints Service
- Manuscript Podcast for convenient understanding
- Global attainment for your research
- Manuscript accessibility in different formats
( Pdf, E-pub, Full Text, Audio)
- Unceasing customer service
Track the below URL for one-step submission
https://juniperpublishers.com/online-submission.php

